\title{
LA DEMOCRACIA Y LOS DERECHOS HUMANOS: UNA RELACIÓN COMPLEJA
}

\author{
Isabel Villaseñor Alonso
}

\section{INTRODUCCIÓN}

Robert Alexy CONSIDERA QUe HAY tres posturas para el entendimiento de la relación entre democracia y derechos humanos: la ingenua, la idealista y la realista. ${ }^{1}$ La primera no reconoce ningún conflicto en las dos nociones puesto que ambas son parte de un mismo ideario que comprende una diversidad de aspectos buenos y deseables de la vida pública de un país, mientras que la segunda postura reconoce conflictos pero aspira a conciliarlos. Finalmente, la tercera visión a la cual me refiero, considera que los derechos humanos son a la vez democráticos y antidemocráticos.

Como analizaré más adelante, las obligaciones generales y el Derecho Internacional de los Derechos Humanos, así como ciertas aproximaciones y filosofías políticas, implican la subordinación de la democracia a los derechos humanos, aunque un entendimiento sustancial de la democracia no considera esto como una limitante o un aspecto negativo, pues los derechos humanos forman parte de la esencia misma de la democracia.

Existen Estados cuyo reconocimiento como regímenes democráticos se basa simplemente en la existencia de elecciones limpias y periódicas -democracias formales o procedimentales-, mientras que otras democracias no sólo contemplan estas acciones sino que

${ }^{1}$ Robert Alexy, "Los derechos fundamentales en el Estado Constitucional Democrático”, en Miguel Carbonell (ed.), Neoconstitucionalismo, Madrid, Trotta, 2003, p. 38. 
también buscan ideales o contenidos ético-políticos, como el respeto a los derechos humanos y la igualdad socioeconómica y de oportunidades de los individuos. Es decir, existen democracias formales o "sin adjetivos" en contraposición con otras que, además de ser formales, buscan también ciertos ideales. ${ }^{2}$ Es así que en un primer análisis la relación entre democracia y derechos humanos se torna compleja. Mientras que las democracias formales pueden tener muy poca relación con el ejercicio de los derechos humanos, las democracias sustanciales requieren forzosamente un apego a los derechos humanos, no sólo aquéllos civiles y políticos, sino también a los derechos económicos, sociales, culturales y ambientales (DESCA).

También cabe hacer mención de las configuraciones y cambios institucionales específicos que se requieren para que una democracia derive en el ejercicio pleno de los derechos humanos. En este sentido, Davenport y Armstrong, con base en un análisis estadístico de las prácticas de 149 Estados democráticos durante dos décadas, identifican claramente que, a cierto nivel, la adopción de prácticas democráticas no tiene ningún impacto para disminuir las violaciones de derechos humanos. ${ }^{3}$ Sin embargo, pasado el umbral de la consolidación democrática, en donde se efectúan cambios estructurales que transforman a la sociedad y a las instituciones, la democracia tiene un claro efecto para disminuir la represión y las violaciones de derechos humanos por parte del Estado.

\section{LA RELACIÓN DEMOCRACIA-DERECHOS HUMANOS A LA LUZ DE LAS FILOSOFÍAS POLÍTICAS}

La relación entre democracia y derechos humanos también es configurada según el orden político existente y el predominio de ciertas filosofías políticas, así como la manera que éstas tienen de entender al individuo y de priorizar los derechos humanos. Con

${ }^{2}$ Michelangelo Bovero, Una gramática de la democracia. Contra el gobierno de los peores, Madrid, Trotta, 2000, p. 48.

${ }^{3}$ Christian Davenport y David A. Armstrong, "Democracy and the Violation of Human Rights", American Journal of Political Science, vol. 48, núm. 3, 2004, pp. 538-554. 
esto quiero decir que los distintos tipos de Estados democráticos configurados bajo filosofías políticas específicas- se confrontan en distinta medida con los derechos humanos. Si bien todos los regímenes democráticos reconocen las libertades fundamentales, las diferencias son notables con respecto a muchos derechos políticos y en relación a los DESCA.

En el caso de los Estados liberales, la relación democracia-derechos humanos es compleja, pues el liberalismo privilegia de manera clara los derechos individuales sobre los derechos colectivos, así como las libertades y la propiedad privada sobre la soberanía popular y los Desca. Esto se debe a que la ética del liberalismo se basa en la competencia de los individuos y cuestiona las estructuras colectivas. ${ }^{4}$

El privilegiar las libertades individuales por sobre otros derechos promueve indirectamente la desigualdad social ya que los Estados no impulsan políticas públicas que compensen las asimetrías económicas y sociales. ${ }^{5}$ El Estado "neutro" del liberalismo, entendido como un mal necesario cuyo deber es no interferir, ${ }^{6}$ genera que la fuerza del mercado sea desproporcionada porque no existe un elemento que pueda servir de contrapeso, lo que deja a muchos grupos en situación de vulnerabilidad. Incluso Nozick entiende como derechos a las fronteras que protegen las esferas de acción de los individuos, y asocia el "derecho a perseguir los propios fines", como el derecho a la propiedad privada, incluso cuando esto signifique una desigualdad socioeconómica notable. ${ }^{7}$

De igual manera, las distintas filosofías políticas tienen distintas maneras de entender la libertad. Mientras que el liberalismo, por ejemplo, la entiende como libertad negativa o de no interferencia, el republicanismo la entiende como libertad positiva o de no dominación. Como analiza Pettit, la libertad positiva no sólo requiere hacer frente a los factores externos, sino también a aquéllos internos,

${ }^{4}$ B. Amable, "Morals and Politics in the Ideology Of Neo-Liberalism", SocioEconomic Review, vol. 9, núm. 1, 2011, pp. 3-30.

${ }^{5}$ Francisco Panizza, "Human Rights in the Processes of Transition and Consolidation of Democracy in Latin America”, Political Studies, vol. 43, 1995, pp. 168-188.

${ }^{6}$ Cfr. Robert Nozick, Anarquía, Estado y Utopia, México, FCE, 1988.

${ }^{7}$ David Held, Modelos de democracia, México, Alianza, 1992, p. 296. 
como la debilidad y la ignorancia. ${ }^{8}$ El estatus del individuo en el republicanismo consiste en su posibilidad para autodeterminarse, para hacer de él mismo lo que se desea hacer, participando con una virtud cívica en una comunidad de personas libres e iguales. ${ }^{9}$

Es así que la democracia, pensada desde las distintas filosofías políticas, adquiere distintas posturas hacia los derechos humanos. Mientras que al liberalismo libertario le bastan los derechos civiles y políticos, el republicanismo demanda el desarrollo cabal de los individuos, que a su vez requiere del cumplimiento de los derechos económicos, sociales y culturales. Esto es así porque el desarrollo integral de los individuos requiere necesariamente de una buena salud, educación y pertenencia a sistemas culturales, para lo cual se requieren acciones positivas mediante políticas públicas que garanticen estos derechos a todos los individuos.

De igual manera, la noción de igualdad es radicalmente distinta en estas dos filosofías políticas. Para el liberalismo, la igualdad consiste simplemente en la igualdad de los individuos ante la ley en tanto sujetos de derecho, así como la igualdad moral e igualdad política, y es precisamente esta igualdad de los individuos como sujetos portadores de derechos y responsables de sus propias acciones de donde se deriva el vínculo con la democracia. ${ }^{10}$ Sin embargo, la manera de concebir la igualdad por parte del republicanismo es diametralmente distinta. Gran parte de los pensadores republicanos, siguiendo las ideas de Catón, coinciden en que la igualdad política depende de la igualdad económica, ya que la igualdad de bienes conlleva una igualdad de poder, y una igualdad de poder es una democracia. ${ }^{11}$ Es decir, para el republicanismo no basta la igualdad abstracta (igualdad moral, política y ante la ley), sino que se requiere una igualdad sustancial, o sea, una igualdad de capacidades en donde no se vuelvan invisibles las diferencias y asimetrías

${ }^{8}$ P. Pettit, "Liberalismo y republicanismo", en F. Ovejero et al. (eds.), Nuevas ideas republicanas, Barcelona, Paidós, 2004, p. 118.

${ }^{9}$ J. Habermas, "Derechos humanos y soberanía popular: Las concepciones liberal y republicana”, Revista Derechos y Libertades, 3, 1994, p. 224.

10 Guillermo O'Donnell, Polyarchies and the Un(Rule) of Law in Latin America, Working Paper \#254. Instituto Juan March de Estudios e Investigaciones, 1998, p. 15.

${ }^{11}$ Pettit, op. cit., p. 156. 
sociales y económicas, y en donde los individuos puedan autodeterminarse.

Otra noción relevante para el republicanismo es la del bien común, entendido como todo aquello de lo que se benefician los miembros de una comunidad, aun cuando existe diversidad de intereses e ideologías y por lo tanto también choques de derechos. Según el republicanismo, es necesario que los ciudadanos estén a cargo de los asuntos públicos ya que toda persona, una vez en el poder, tenderá a promover sus propios intereses sobre aquéllos de la comunidad. ${ }^{12}$ Es por esta razón por la cual el concepto de ciudadanía -pertenencia y participación en una comunidad- es fundamental para el republicanismo, y es precisamente la participación política la que requiere la virtud cívica de los individuos, misma que se logra mediante el cumplimiento de los DEscA.

Una vez resaltadas las principales diferencias entre el liberalismo y el republicanismo, cabe señalar que existen distintas posturas dentro del liberalismo, así como distintas formas de configuración política de los Estados liberales. La filosofía política de Rawls, por ejemplo, se acerca más al republicanismo y propone un liberalismo igualitario en donde las libertades no sean concebidas sin la igualdad de oportunidades. ${ }^{13}$ Es decir, las implicaciones para la relación democracia-derechos humanos desde el liberalismo igualitario consisten en que el enriquecimiento y empoderamiento de unos cuantos, y la consiguiente desigualdad socioeconómica, implican la inexistencia de una igualdad de oportunidades para que los individuos puedan autodeterminarse políticamente, lo que impide el desarrollo de una vida democrática.

Tras este breve análisis podemos ver que el entendimiento del individuo, así como de las nociones de libertad e igualdad, tienen implicaciones para la relación democracia-derechos humanos. Mientras que el liberalismo libertario considera únicamente a los derechos civiles y políticos como prerrequisitos de una vida democrática, el

${ }^{12}$ Quentin Skinner, “The State”, en Terence Ball, James Farr y Russel L. Hanson (eds.), Political Innovation and Conceptual Change, Cambridge, Cambridge University Press, 1989, p. 104.

${ }^{13}$ J. Rawls, "Ideas fundamentales", en Liberalismo Político, 2a ed., México, FCE, 1996, p. 32. 
liberalismo igualitario y el republicanismo demandan también el cumplimiento de los DESCA para lograr una autodeterminación, y por lo tanto una mejor igualdad de oportunidades, todo lo cual es necesario para una verdadera democracia.

Los límites Que el Derecho Internacional de los Derechos Humanos impone a los Estados

El Derecho Internacional de los Derechos Humanos (DIDH), como un ordenamiento supranacional, impone límites a los Estados. A diferencia del derecho internacional, en donde los países firman tratados bilaterales o multilaterales donde se estipulan intereses de cada uno de los mismos y se generan concesiones recíprocas entre los Estados, el DIDH estipula solamente obligaciones pero no derechos para cada uno de los Estados (derecho de carácter objetivo). Esas obligaciones consisten precisamente en respetar los derechos fundamentales de los individuos bajo su jurisdicción. ${ }^{14}$

Los límites que impone el DIDH a los Estados, principalmente a través de convenciones y tribunales regionales de derechos humanos, tienen muchas consecuencias para la relación democracia-derechos humanos. Los países democráticos, además de tener que cumplir con las distintas obligaciones de los derechos humanos, ya no se limitan a la configuración Estado-céntrica que entiende a la soberanía nacional como la total libertad de acción por parte del Estado o incluso como un escudo de impunidad para el mismo -acepción absoluta de la soberanía-, sino que este nuevo ordenamiento los obliga a rendir cuentas a organismos supranacionales sobre su accionar con respecto a los individuos bajo su jurisdicción. En este sentido cabe hacer mención del artículo 27 de la Convención de Viena sobre el Derecho de los Tratados, ${ }^{15}$ en donde se estipula que los Estados no pueden

\footnotetext{
${ }^{14}$ Antônio Cançado Trindade, El Derecho Internacional de los Derechos Humanos en el siglo XXI, Santiago de Chile, Editorial Jurídica de Chile, 2001, p. 22.

${ }^{15}$ onu, Convención de Viena sobre el Derecho de los Tratados, Organización de las Naciones Unidas, 1969.
} 
apelar a la legislación interna para no cumplir con sus obligaciones convencionales.

Como analizan Levy y Sznaider, esta nueva configuración no representa una merma para la soberanía nacional, pero la base de la legitimidad ya no se determina a nivel estatal, sino por la medida en que los Estados aceptan su compromiso con el cumplimiento de los derechos humanos. ${ }^{16}$ Es así que los Estados son libres de organizarse en su ordenamiento interior siempre y cuando cumplan con las obligaciones del DIDH.

Por esta razón, el DIDH hace más estrecha la relación entre democracia y derechos humanos, ya que, aunado a la legitimidad demandada en la arena internacional para la formación de Estados democráticos, se demanda que dichos Estados tengan un compromiso serio con los derechos humanos. Esta fusión de derechos humanos y democracia constituye, según Ferrajoli, el nuevo paradigma del Estado constitucional de derecho. ${ }^{17}$

Ferrajoli también destaca que la crisis de los Estado-nación supone además un cambio de paradigmas en donde se exponen las antinomias tradicionales de ciudadanía y soberanía por una parte, y constitucionalismo y derechos humanos por la otra. ${ }^{18}$ Este cambio se gestó desde la Declaración Universal de los Derechos Humanos y los posteriores pactos de 1966, en donde el sistema construido en relaciones bilaterales entre países soberanos se transformó en un orden jurídico global. La soberanía perdió fuerza tanto en su ámbito interno como en el externo, al igual que la ciudadanía se debilitó ante el universalismo de los derechos humanos. Es así que se puede observar la génesis de una constitución global en los tratados de derechos humanos, que si bien aún carece de garantías constitucionales, se encuentra ya formalmente

${ }^{16}$ Daniel Levy y Natan Sznaider, "Sovereignty Transformed: A Sociology of Human Rights”, The British Journal of Sociology, vol. 57, núm. 4, 2006, pp. 657-676.

17 Ferrajoli, "Sobre los derechos fundamentales", Cuestiones Constitucionales, núm. 15, 2006, p. 114.

${ }^{18}$ Luigi Ferrajoli, "Más allá de la soberanía y la ciudadanía: un constitucionalismo global”, en Richard Bellany (ed.), Constitucionalismo, democracia y soberanía, Averbury, 1996. 
establecida, ${ }^{19}$ lo que da cuenta de la progresiva fuerza que tiene el DIDH sobre los Estados democráticos.

Sin embargo, a pesar de que normativamente el DIDH hace más estrecha la relación democracia-derechos humanos a nivel mundial, en la vía de los hechos se produce una notoria tensión entre ambos. Esto sucede porque el DIDH, como ordenamiento supranacional, impone límites a las democracias en tanto configuraciones estatales. En este sentido, podemos encontrar cuantiosos ejemplos en las sentencias condenatorias de los tribunales regionales de derechos humanos contra los distintos Estados. En el caso de México, el Estado ha sido condenado en numerosas ocasiones por la Corte Interamericana de Derechos Humanos. Algunas sentencias notorias han sido el Caso González y otras "Campo Algodonero vs. México”, y el caso Rosendo Radilla vs. México, ${ }^{20}$ en los que se ha condenado la violación del derecho a la vida y a la integridad física y se han desarrollado estándares de garantías judiciales.

En suma, el DIDH impone límites claros a las democracias. Si bien normativamente eso no implica ninguna confrontación en la relación democracia-derechos humanos, en la realidad existen muchos factores que tensan esta relación, especialmente porque los Estados democráticos deben cumplir con lo estipulado por el DIDH, configurado en ordenamientos supraestatales.

\section{LAS OBLIGACIONES GENERALES DE LOS DERECHOS HUMANOS}

Con relación al punto anterior en donde el DIDH señala límites a los Estados, las obligaciones generales demandan a los países respetar, proteger, promover y garantizar los derechos humanos. Estas obligaciones se encuentran estipuladas en la Convención

\footnotetext{
${ }^{19}$ Ferrajoli, "Más allá de la soberanía y la ciudadanía: un constitucionalismo global".

${ }^{20}$ Corte IDH, Caso González y otras ("Campo Algodonero") Vs. México. Excepción Preliminar, Fondo, Reparaciones y Costas. Sentencia de 16 de noviembre de 2009. Serie C núm. 205, párrafo 306. Corte IDH. Caso Radilla Pachecoo vs Estados Unidos Mexicanos. Excepciones Preliminares, Fondo, Reparaciones y Costas. Sentencia de 23 de noviembre de 2009. Serie C No. 209, párrafo 298.
} 
Americana sobre Derechos Humanos, ${ }^{21}$ el instrumento del DIDH más importante para los países del continente americano.

La obligación de respetar consiste en no violar los derechos humanos, por lo que constituye simplemente una acción negativa o de no interferencia. La obligación de proteger implica que el Estado debe proteger a las personas de la violación de derechos humanos cometida por particulares. Por otra parte, la obligación de promover implica poner a la disposición de la sociedad la información necesaria para que los individuos conozcan sus derechos y sepan cómo ejercerlos. Finalmente, la obligación de garantizar consiste en asegurar que todos los individuos estén en posibilidad de ejercer efectivamente el pleno goce de los derechos humanos. ${ }^{22}$

A excepción de la obligación de respetar, el resto de las obligaciones acarrean no sólo una acción de abstención, sino que demandan también acciones positivas, ya que los Estados tienen que organizar todo el aparato gubernamental para poder efectuar campañas públicas y mecanismos de difusión para informar a la población sobre sus derechos, así como una serie de políticas públicas para prevenir, investigar y sancionar las violaciones de los derechos humanos y reparar los daños. ${ }^{23}$ Es precisamente esta serie de acciones positivas, que incluyen la adopción de medidas legislativas y reformas institucionales, la que provoca tensión entre los derechos humanos y la democracia. Una vez más, los países no están en posibilidad de llevar al grado absoluto el ejercicio de su democracia como Estados soberanos, sino que la vida democrática debe ajustarse al respeto, protección, promoción y garantía de los derechos humanos.

Medina ejemplifica las implicaciones de dichas acciones positivas con el derecho al debido proceso, dado que éste requiere que el Estado adopte medidas legislativas en torno al derecho procesal, cree escuelas de derecho donde se capaciten abogados, provea

21 oEA, Convención Americana sobre Derechos Humanos, San José de Costa Rica, Organización de Estados Americanos, noviembre de 1969.

22 Cecilia Medina, La convención americana: vida, integridad personal, libertad personal, debido proceso y recurso judicial, Chile, Universidad de Chile, 2003, p. 18.

${ }^{23}$ Comité de Desc, Observación General No. 3. La indole de las obligaciones de los Estados Parte, 1990. 
asistencia legal gratuita y fortalezca los tribunales. ${ }^{24}$ De igual manera, por ejemplo, para garantizar los derechos reproductivos de las mujeres, el Estado debe adoptar leyes al respecto, crear o fortalecer instituciones de salud pública, capacitar a médicos y emprender campañas públicas con perspectiva de género. Todas estas acciones positivas implican una gran inversión de recursos que no necesariamente son propuestos por los legisladores o funcionarios elegidos democráticamente.

Es así que, nuevamente, los derechos humanos vuelven a dictar una manera de proceder, limitando hasta cierto punto la total libertad de acción por parte del Estado. Sin embargo, las directrices marcadas por los derechos humanos no determinan las reformas institucionales o legislativas específicas a llevar a cabo, ya que los Estados pueden adoptar diversas acciones y políticas públicas para lograr los mismos objetivos. Es decir, para lograr una misma meta, los Estados pueden buscarla mediante distintas reformas institucionales y acciones de diversa índole. Es por ello que, si bien las obligaciones generales de los derechos humanos marcan límites a los Estados y en ese sentido subsumen la democracia a los derechos humanos, esto no implica una merma en la vida democrática de un país, entendida ésta desde una visión sustancial de la democracia.

\section{LA RELACIÓN DEMOCRACIA-DERECHOS HUMANOS EN LAS GARANTÍAS PRIMARIAS}

$\mathrm{Al}$ incorporar las garantías primarias de los derechos humanos -especialmente el elevar los derechos humanos a rango constitucional-, un Estado democrático adopta los derechos humanos como una política de Estado y les confiere una legitimidad que por sí misma contribuye al fortalecimiento de su ejercicio. Es así que se vuelve más complicado para los agentes estatales violar abiertamente los derechos humanos, lo que sí sucede cuando el discurso de los derechos humanos no está legitimado por la opinión pública. A

${ }^{24}$ Medina, op. cit., p. 20. 
esto se añade la vivencia de los derechos humanos, que consiste en la manera en que los individuos hacen suyo el discurso de los derechos humanos y emplean los distintos mecanismos para exigir su cumplimiento.

Un aspecto esencial de otorgar rango constitucional a los derechos humanos es que la constitución se convierte en la garantía de contenido de los mecanismos de exigibilidad primarios, pues impide que se adopte legislación contraria a los derechos humanos. No obstante, la constitucionalización de los derechos humanos implica cierta tensión entre la democracia y los derechos humanos, dado que los congresos, como órganos democráticamente elegidos, se ven limitados en su labor debido a que las leyes deben apegarse a los derechos humanos.

Sin embargo, aquí cabe hacer una reflexión acerca del valor de la democracia entendida en sentido absoluto y la democracia sustancial entendida desde el neoconstitucionalismo de Luigi Ferrajoli. ${ }^{25}$ La primera enfatiza los procedimientos y el aspecto formal de la democracia, mientras que la segunda resalta la relevancia del respeto a los derechos humanos como parte esencial de todo régimen democrático.

Los demócratas radicales, como Waldron y Dworkin, cuestionan que los derechos fundamentales tengan que estar constitucionalizados, porque eso sugiere una restricción democrática y una tiranía de los antepasados a los que vivimos hoy en día. Sin embargo, como analiza Salazar, ${ }^{26}$ las críticas de los demócratas radicales ponen más énfasis en la forma que en el contenido, ya que paradójicamente la restricción en la acción legislativa, dictada por los principios éticos constitucionalizados, es la que permite precisamente la vida democrática de un país. De igual manera, esta contradicción entre la democracia y los derechos humanos constitucionalizados se subsana debido a que la constitución tiene

${ }^{25}$ Ferrajoli, "Pasado y futuro del estado de derecho", en Miguel Carbonell (ed.), Neoconstitucionalismo(s), Madrid, Trotta, 2003; y del mismo autor: "La soberanía en el mundo moderno”, en Derechos y Garantías. La ley del más débil, Madrid, Trotta, 2004, pp. 125-158.

${ }^{26}$ Pedro Salazar, La democracia constitucional: una radiografía teórica, México, FCE, 2006, p. 203. 
una validez democrática en tanto que fue creada por un poder constituyente. ${ }^{27}$

Es así que la democracia sustancial y el neoconstitucionalismo privilegian a los derechos humanos sobre los postulados positivistas de la democracia, entendida en su acepción absoluta como total libertad de los legisladores electos democráticamente. Así, el neoconstitucionalismo parte de la idea de que las leyes son la manera de cristalizar los ideales y principios éticos estipulados en la constitución, y cuestiona la total libertad en la expresión del poder político.

Una restricción similar es aplicable a los mecanismos secundarios (mecanismos jurisdiccionales) debido a que los jueces de tribunales y otras instancias jurisdiccionales deben apegarse a los derechos humanos en la resolución de los casos y la interpretación de la ley. Sin embargo, esto no representa una confrontación directa entre la democracia y los derechos humanos, dado que los jueces no suelen ser elegidos democráticamente.

\section{LA POSICIÓN DE LOS DERECHOS HUMANOS EN LOS DISTINTOS} MODELOS DE DEMOCRACIA

La diversidad de regímenes democráticos en relación al grado de consulta y participación ciudadana (democracias representativas vs. democracias directas o participativas y la diversidad que existe entre estos dos tipos) también representa diferencias con respecto a su relación con los derechos humanos. De manera general, podemos decir que la democracia representativa consiste en la elección de gobernantes que representan los intereses de los gobernados en un marco liberal de imperio de la ley, mientras que la democracia directa incluye una serie de instrumentos que permiten a los ciudadanos participar activamente en las decisiones del gobierno. Sin embargo, además de la diversidad en los modelos de democracia, existe una diversidad de formas en que la democracia se puede configurar. ${ }^{28}$ 
Lo relevante para el análisis de la relación democracia-derechos humanos es la manera como los distintos modelos de democracia conciben al individuo en tanto sujeto de derecho. En este sentido, la democracia representativa, especialmente en su versión formal o procedimental, según la plantean Shumpeter y Dahl, ${ }^{29}$ pone el énfasis en la igualdad formal de los individuos, lo que para efectos del ejercicio democrático se traduce en la necesidad de celebrar elecciones periódicas donde todos los votos cuentan y cada voto vale lo mismo (igualdad de voto). La democracia en este modelo no tiene un fin ético, solamente busca la configuración de un orden político basado en la elección de gobernantes. Para lograr dicho objetivo, lo que se requiere es el respeto a ciertos derechos civiles y políticos, tales como la libertad de expresión, la libertad de asociación y el derecho a votar y a ser votado. Sin embargo, el resto de los derechos no son contemplados como prerrequisitos para alcanzar una democracia. Este modelo democrático está fundamentado en la filosofía política liberal, misma que, como ya se mencionó, entiende al individuo como el centro del orden político, asume igualdad moral entre los individuos y demanda la libertad negativa o no interferencia del Estado, por lo que los derechos económicos, sociales y culturales no son contemplados.

Un claro ejemplo de lo anterior es México en los años recientes, pues, a pesar de existir democracia-cuestionable desde el punto de vista sustancial, esta democracia ha coexistido con una violación rampante de los derechos humanos, infringida en gran medida por los cuerpos de seguridad del Estado en el marco de la guerra frontal contra los grupos del crimen organizado. Las violaciones más graves incluyen numerosos casos de tortura con el fin de obtener confesiones, así como desapariciones forzadas y ejecuciones extrajudiciales llevadas a cabo por militares, marinos y policías federales y estatales. ${ }^{30}$ Aun cuando

${ }^{29}$ Joseph Schumpeter y José Díaz García, Capitalismo, socialismo y democracia, tomo 1, Barcelona, Ediciones Orbis, 1983; Robert Dahl, A Preface to Democratic Theory, University of Chicago Press, 2013.

${ }^{30}$ Human Rights Watch, Neither Rights Nor Security: Killings, Torture and Disappearances in Mexico's "War on Drugs", Reporte de Human Rights Watch, 9 de 
existe un Instituto Nacional Electoral (antes Instituto Federal Electoral) y se celebran elecciones "limpias" y periódicas, la violación a los derechos humanos en México ha llegado a niveles de crisis humanitaria. ${ }^{31}$ Adicionalmente, existe una desigualdad social que da cuenta de la falta de cumplimiento de los DESCA. Es decir, debido a que la democracia en México es entendida desde una visión formal o procedimental, las violaciones a los derechos humanos no restan legitimidad a las prácticas democráticas.

Por otra parte, las democracias directas y participativas conciben al individuo de distinta manera. De manera similar al republicanismo, estas democracias consideran indispensable el desarrollo de las capacidades de los individuos, así como la virtud cívica expresada por medio de la participación en los asuntos públicos. ${ }^{32} \mathrm{El}$ derecho a desarrollar estas capacidades y la virtud cívica, por tanto, requieren no sólo de la selecta gama de derechos civiles y políticos para la elección periódica de gobernantes, sino del más alto grado de salud, educación y bienestar social, lo que, como ya se ha mencionado a lo largo del escrito, depende de acciones positivas que garanticen los DESCA.

De la misma forma, aun cuando la democracia participativa no está libre de ciertos problemas como la manipulación o la demagogia, la amplia participación ciudadana de este modelo tiende a incorporar decisiones en beneficio de los distintos grupos sociales, lo cual es logrado mediante los distintos instrumentos de la democracia directa (referéndum, iniciativa popular y revocación del mandato). ${ }^{33}$

noviembre de 2011. Disponible en http:/ /www.hrw.org/reports/2011/11/09/ neither-rights-nor-security-0

${ }^{31}$ C. Infante, A. J. Idrovo, M. S. Sánchez-Domínguez, S. Vinhas y T. GonzálezVázquez, "Violence Committed against Migrants in Transit: Experiences on the Northern Mexican Border", Journal of Immigrant and Minority Health, vol. 14, núm. 3, 2012, pp. 449-459.

${ }^{32}$ Held, op. cit., p. 129.

33 Jean-François Prud'homme, Consulta popular y democracia directa, México, Instituto Federal Electoral, 1997, pp. 19-24. 


\section{LOS DERECHOS HUMANOS EN LA CONFORMACIÓN DEL ESTADO} DE DERECHO Y SU RELACIÓN CON UN ESTADO DEMOCRÁTICO

Aun cuando no existen definiciones consensuadas sobre los términos "Estado de derecho", "Estado democrático de derecho" y "Estado constitucional de derecho", se puede afirmar que cada uno de ellos tiene un énfasis distinto.

El primer término, Estado de derecho, al igual que la democracia, puede definirse con visiones formales y sustantivas. Raz, Summers y O'Donnell ${ }^{34}$ confieren visiones formales que se acercan más a la definición de "imperio de la ley", es decir, el control del gobierno mediante determinadas normas. Por otra parte, se encuentran los autores que otorgan una definición más sustancial al Estado de derecho, como Díaz y Vázquez. ${ }^{35}$ Este último, por ejemplo, desde una perspectiva liberal igualitaria reconoce que no basta la primacía de la ley, sino que también se necesita la responsabilidad de los funcionarios, el control judicial de constitucionalidad y el respeto de los derechos humanos. Una vez más, los derechos humanos se vuelven condición fundamental de las visiones sustanciales. Aunque no son un requerimiento para la existencia y respeto a las leyes, sí forman parte esencial de una visión sustantiva en donde las leyes están dotadas de contenido ético.

Por su parte, la noción de Estado democrático de derecho denota no sólo el respeto a la ley, sino también los rasgos y mecanismos que constituyen a la democracia. Sin embargo, como ya se discutió previamente, no sólo existe una gran diversidad de modelos

${ }^{34}$ Joseph Raz, "El Estado de derecho y su virtud”, en Miguel Carbonell, Wistano Orozco y Rodolfo Vásquez (coords.), Estado de derecho: Concepto, fundamentos y democratización en América Latina, México, Siglo XXI, 2002, pp. 15-36; Robert Summers, "Los principios del Estado de derecho", en Miguel Carbonell, Wistano Orozco y Rodolfo Vásquez (eds.), Estado de derecho: Concepto, fundamentos y democratización en América Latina, México, Siglo XXI, 2002, pp. 37-59; O’Donnell, op. cit.

${ }^{35}$ Elías Díaz, "Estado de derecho y legitimidad democrática", en Miguel Carbonell, Wistano Orozco y Rodolfo Vázquez (eds.), Estado de derecho: concepto, fundamentos y democratización en América Latina, México, Siglo XXI, 2002, pp. 61-95; Vázquez, "Violence Committed against Migrants in Transit: Experiences on the Northern Mexican Border", Journal of Immigrant and Minority Health, vol. 14, núm. 3, 2012, pp. 449-459. 
de democracia, sino también un amplio rango de visiones normativas sobre ella, por lo que existen también diversas aproximaciones a la noción de Estado democrático.

Lo que es relevante para el análisis de la relación democraciaderechos humanos es la manera en que los derechos humanos guían y acotan los ejercicios democráticos. Para el Estado democrático de derecho, cuando se piensa en la inclusión de los derechos humanos, éstos claramente toman una posición privilegiada sobre la democracia, pues, como menciona Ferrajoli, ${ }^{36}$ a las mayorías se les debe sustraer el poder de suprimir el poder de las minorías. Como un ejemplo, puede existir un plebiscito para aprobar la pena de muerte o la expulsión masiva de migrantes indocumentados -lo cual sería un ejercicio democrático en una visión formal-; esto podría ejecutarse con apego a la ley -lo cual sería válido en un imperio de la ley o una visión formal del Estado de derecho-, pero no podría existir desde una visión sustantiva del Estado de derecho en donde se consideren los derechos humanos y donde éstos tengan un papel preponderante sobre la democracia.

En esta discusión también cabe mencionar el término Estado constitucional de derecho, el cual dota de contenido ético al derecho e impide la adopción de leyes contrarias a los derechos humanos. Nuevamente, y tal como se discutió en el apartado de garantías primarias, los derechos humanos se privilegian sobre la democracia, dado que los congresos, como órganos elegidos democráticamente, se ven limitados en su acción legislativa por los derechos humanos.

\section{EL EFECTO DE LAS GLOBALIZACIONES EN LA RELACIÓN DERECHOS HUMANOS Y DEMOCRACIA}

Podríamos decir que tanto la conformación de Estados democráticos como el apego a los derechos humanos son en sí mismos

${ }^{36}$ Ferrajoli, "Sobre la definición de democracia", en Luigi Ferrajoli y Michelangelo Bovero, Teoría de la democracia. Dos perspectivas comparadas, México, IFE, 2001, pp. 11-31. (Colección: Temas de la Democracia, Serie: Conferencias magistrales) 
fenómenos de globalización, que aunque surgieron principalmente en el mundo occidental, ahora está configurando gran parte de los ordenamientos políticos de los Estados modernos.

Los distintos fenómenos de globalización y los localismos globalizados, en sus facetas económicas, sociales, políticas y culturales, tienen un efecto importante sobre los derechos humanos y las democracias actuales, así como en la relación entre estos dos. Un ejemplo muy claro es el impacto que tienen los aspectos de globalización económica en el funcionamiento de las democracias con respecto al ejercicio de los derechos humanos. Es innegable que estas globalizaciones conllevan flujos financieros y fuerzas mercantiles que rebasan a las democracias actuales en tanto ordenamientos estatales. Es así que los Estados han perdido fuerza frente a las compañías multinacionales, por lo menos en lo que respecta a su vida económica. En este sentido, las economías de mercado, como aquellas de los países latinoamericanos después de la década de 1970 , han mostrado que la pobreza ha aumentado a pesar del crecimiento económico, es decir, existe una acumulación diferencial del capital que conlleva una creciente desigualdad socioeconómica. ${ }^{37}$ Los grupos favorecidos en este fenómeno son siempre los que constituyen "La Triple Alianza", es decir, las multinacionales, las élites capitalistas locales y la burguesía estatal. ${ }^{38}$ De igual manera, esta acumulación del capital significa en muchos casos una regresión de los derechos económicos, sociales y culturales, ya que los Estados neoliberales favorecen más un clima adecuado para los negocios y la inversión que los derechos colectivos o la calidad de los trabajos. ${ }^{39}$

Cabe señalar en este sentido que las democracias procedimentales y representativas son propensas a dar entrada libre a los mecanismos y efectos de la globalización económica, debido, por una parte, a que la toma de decisiones se da de una manera vertical por los grupos de poder y con poca participación social -sobre todo de

${ }^{37}$ Panizza, op. cit., p. 179.

38 Boaventura de Sousa Santos, La caída del Ángelus Novus: ensayos para una nueva teoría social y una nueva práctica política, Bogotá, ILSA, 2003, p. 174.

${ }^{39}$ David Harvey, A Brief History of Neoliberalism, Nueva York, Oxford University Press, 2007, p. 70. 
los grupos más desfavorecidos-, y por otra parte, porque las democracias representativas están planteadas desde la lógica liberal en donde sólo se contempla la igualdad moral de los individuos pero se hacen invisibles las asimetrías sociales. Es por esta razón que en las democracias procedimentales y representativas los impactos de globalización son más notorios en los derechos económicos y sociales. Como un ejemplo de estas prácticas, está el caso de las reformas estructurales en México, en particular la reforma laboral, la cual implicó una regresión de los derechos laborales, lo que provocó la presentación de millares de amparos.

Para efectos del presente análisis, los fenómenos de globalización económica en democracias representativas tienden a tensar la relación democracia-derechos humanos, específicamente en lo que se refiere a la toma de decisiones con respecto a los DESCA, pues como afirma De Sousa Santos, ${ }^{40}$ los representantes (burguesía estatal que puede ser elegida democráticamente) son una de las partes que se benefician de los procesos de liberalización económica, a expensas de las clases trabajadoras.

Sin embargo, en el caso de las democracias directas y participativas, mismas que implican una mayor horizontalidad y consulta a los distintos grupos sociales, los impactos de la globalización económica en los DESCA son menores en tanto que estas democracias tienden a poner frenos a las reformas estructurales que permiten empoderar a las compañías multinacionales, contribuyendo a la acumulación del capital y a la desvalorización del capital humano. Un ejemplo de esto son las socialdemocracias europeas, las cuales regulan de mejor manera los efectos negativos de las globalizaciones económicas, además de que en estos países los DEScA están más consolidados como resultado de la construcción del Estado de bienestar. ${ }^{41}$

Por otra parte, otro aspecto de la globalización es precisamente el movimiento de los derechos humanos y su institucionalización no sólo a nivel estatal sino en ordenamientos supranacionales.

40 Op. cit.

${ }^{41}$ Paul Pierson, "The New Politics of the Welfare State", World Politics, 1996, p. 145 . 
En este sentido, la globalización es relevante en tanto que las democracias actuales son aceptadas por la comunidad internacional sólo en la medida en que incorporan los derechos humanos como política de Estado. La relación entre democracia y derechos humanos es por lo tanto indisoluble en lo que se refiere a la legitimidad en la arena internacional. Sin embargo, la relación democraciaderechos humanos también es tensa en la vía de los hechos porque los organismos supranacionales de derechos humanos con frecuencia entran en conflicto con las democracias, organizadas como Estados-nación, como ya se mencionó.

Otro rasgo muy relevante de la globalización es la velocidad de los flujos de información, así como la horizontalidad que existe en ciertos medios, como los blogs y las redes sociales, y el impacto que éstos tienen para la concientización y apropiación de los derechos humanos, así como para la denuncia a nivel ciudadano de la información que los Estados tratan de contener en relación a las violaciones por parte de los mismos Estados. Es decir, si bien las democracias actuales intentan legitimarse en la esfera internacional por medio del discurso de los derechos humanos, los fenómenos de la globalización relacionados con los flujos de información presionan a los Estados a adecuar su accionar conforme a la retórica empleada frente a la comunidad internacional. Lo relevante para efectos del presente análisis es que los flujos de información están reconfigurando tanto las prácticas democráticas como los derechos humanos, así como la relación entre ambos. Muchos de estos medios de información están hasta cierto punto democratizados, lo que contribuye a empoderar a la gente y a difundir la información que puede actuar en beneficio de los derechos humanos, tanto con fines de denuncia como a nivel de apropiación de discursos y vivencia de los derechos humanos.

\section{Conclusiones}

A pesar de que la democracia y los derechos humanos forman parte de un mismo ideario en la legitimidad de los Estados-nación, la relación entre ambos es, en muchos aspectos, una relación en 
tensión en donde la democracia se confronta con los derechos humanos.

Las distintas filosofías políticas, así como los distintos modelos democráticos, entienden al individuo de distinta manera, lo que conlleva una aproximación distinta a los derechos humanos en tanto que son los individuos quienes se constituyen como sujetos de derecho. El liberalismo libertario y la democracia representativa coexisten adecuadamente con los derechos civiles y políticos, pero se confrontan de manera importante con los DESCA. Esto se debe a que en estas filosofías políticas se busca un Estado neutro puesto que los individuos son iguales ante la ley, lo que torna invisibles las asimetrías y desigualdades sociales y libera al Estado de su compromiso con los DESCA. Sin embargo, el liberalismo igualitario, el republicanismo y la democracia participativa tienden a promover en mayor medida los DESCA para lograr el desarrollo cabal de los individuos y permitir así su autodeterminación.

Una de las mayores confrontaciones de la democracia con los derechos humanos, según la visión de los demócratas radicales, se depara en la restricción legislativa a la que se ven sometidos los congresos porque éstos, a pesar de haber sido elegidos democráticamente, se ven limitados en su accionar por los derechos humanos, especialmente cuando éstos están constitucionalizados. Sin embargo, desde una óptica del neoconstitucionalismo, el contenido ético de las leyes es éticamente superior a la elección democrática de los legisladores puesto que los derechos humanos son parte esencial de todo régimen democrático. De manera similar, las obligaciones generales de los derechos humanos imponen límites a la democracia porque requieren la instrumentación de una serie de acciones positivas que no necesariamente son promovidas por los representantes elegidos democráticamente.

El DIDH, incluyendo las convenciones, la jurisprudencia de las cortes y las observaciones de los comités, ha enfatizado que los derechos humanos deben privilegiarse en todo momento, lo que en muchos sentidos restringe la libertad absoluta para el ejercicio de la democracia, en particular en el entendimiento tradicional de los Estados-nación como configuraciones políticas soberanas. 
Con respecto a las nociones de Estado de derecho y Estado democrático de derecho, podemos afirmar que al igual que la democracia, su entendimiento desde una perspectiva formal o sustancial conlleva una comprensión distinta con respecto a la inclusión de los derechos humanos. El Estado constitucional de derecho, por otra parte, implica el apego a los contenidos éticos consagrados en la constitución, por lo que cuando los derechos humanos están constitucionalizados se gesta una relación indisoluble entre el Estado de derecho y los derechos humanos.

Ciertos fenómenos de globalización, especialmente los flujos de información, fomentan el ejercicio de los derechos humanos. Sin embargo, el fortalecimiento de las compañías multinacionales suele impactar de manera negativa en los derechos económicos y sociales.

A pesar de que esta reflexión da cuenta de la tensión que existe entre la democracia y los derechos humanos, en ningún caso los derechos humanos atentan contra la democracia entendida en su definición sustancial, ya que ésta entiende el ejercicio democrático de una manera más compleja y siempre en virtud de los ideales éticos y políticos, y en concreto con el cumplimiento de los derechos humanos.

\section{BibLIOGRAFÍA}

Alexy, Robert, "Los derechos fundamentales en el Estado Constitucional Democrático", en Miguel Carbonell (ed.), Neoconstitucionalismo, Madrid, Trotta, 2003.

Amable, B., "Morals and Politics in the Ideology Of Neo-Liberalism", Socio-Economic Review, vol. 9, núm. 1, 2011, pp. 3-30.

Bovero, Michelangelo, Una gramática de la democracia. Contra el gobierno de los peores, Madrid, Trotta, 2000.

Cançado Trindade, Antônio, El Derecho Internacional de los Derechos Humanos en el siglo XXI, Santiago de Chile, Editorial Jurídica de Chile, 2001.

Dahl, Robert, A Preface to Democratic Theory, University of Chicago Press, 2013.

Davenport, Christian y David A. Armstrong, "Democracy and the Violation 
of Human Rights", American Journal of Political Science, vol. 48, núm. 3, 2004, pp. 538-554.

De Sousa Santos, Boaventura, La caída del Ángelus Novus: ensayos para una nueva teoría social y una nueva práctica política, Bogotá, ILSA, 2003.

Díaz, Elías, "Estado de derecho y legitimidad democrática", en Miguel Carbonell, Wistano Orozco y Rodolfo Vázquez (eds.), Estado de derecho: concepto, fundamentos y democratización en América Latina, México, Siglo XXI, 2002, pp. 61-95.

Ferrajoli, Luigi, "Más allá de la soberanía y la ciudadanía: un constitucionalismo global”, en Richard Bellany (ed.), Constitucionalismo, democracia y soberania, Averbury, 1996.

-, "Sobre la definición de democracia", en Luigi Ferrajoli y Michelangelo Bovero, Teoría de la democracia. Dos perspectivas comparadas, México, IFE, 2001, pp. 11-31. (Colección: Temas de la Democracia, Serie: Conferencias Magistrales)

_- "Pasado y futuro del Estado de derecho", en Miguel Carbonell (ed.), Neoconstitucionalismo(s), Madrid, Trotta, 2003.

-, "La soberanía en el mundo moderno", en Derechos y Garantías. La ley del más débil, Madrid, Trotta, 2004, pp. 125-158.

—, "Sobre los derechos fundamentales", Cuestiones Constitucionales, núm. 15, 2006, pp. 114-136.

— Luigi Ferrajoli y Miguel Carbonell, Democracia y garantismo, Madrid, Trotta, 2013.

Habermas, J., "Derechos humanos y soberanía popular: Las concepciones liberal y republicana”, Revista Derechos y Libertades, 3, 1994, pp. 215-230.

Harvey, David, A Brief History of Neoliberalism, Nueva York, Oxford University Press, 2007.

Held, David, Modelos de democracia, México, Alianza, 1992.

Infante, C., A. J. Idrovo, M. S. Sánchez-Domínguez, S. Vinhas y T. González-Vázquez, "Violence Committed against Migrants in Transit: Experiences on the Northern Mexican Border", Journal of Immigrant and Minority Health, vol. 14, núm. 3, 2012, pp. 449-459.

Levy, Daniel y Natan Sznaider, "Sovereignty Transformed: A Sociology of Human Rights", The British Journal of Sociology, vol. 57, núm. 4, 2006, pp. 657-676.

Medina, Cecilia, La convención americana: vida, integridad personal, libertad personal, debido proceso y recurso judicial, Chile, Universidad de Chile, 2003. 
Nozick, Robert, Anarquía, Estado y Utopía, México, FGE, 1988.

O'Donnell, Guillermo, Polyarchies and the Un(Rule) of Law in Latin America, Working Paper \#254. Instituto Juan March de Estudios e Investigaciones, 1998.

—, "La irrenunciabilidad del Estado de derecho", Instituciones y Desarrollo, vol. 8, núm. 9, 2001.

Panizza, Francisco, "Human Rights in the Processes of Transition and Consolidation of Democracy in Latin America", Political Studies, vol. 43, 1995, pp. 168-188.

Pettit, P., "Liberalismo y republicanismo", F. Ovejero et al. (eds.), Nuevas ideas republicanas, Barcelona, Paidós, 2004, pp. 115-135.

Pierson, Paul, “The New Politics of the Welfare State”, World Politics, 1996, pp. 143-179.

Prud'homme, Jean- François, Consulta populary democracia directa, México, Instituto Federal Electoral, 1997. (Cuadernos de Divulgación de la Cultura Democrática, núm. 15)

Rawls, J., "Ideas fundamentales", en Liberalismo Político, 2ª ed., México, FCE, 1996.

Raz, Joseph, "El Estado de derecho y su virtud", en Miguel Carbonell, Wistano Orozco, y Rodolfo Vásquez (coords.), Estado de derecho: Concepto, fundamentos y democratización en América Latina, México, Siglo XXI, 2002, pp. 15-36.

Salazar, Pedro, La democracia constitucional: una radiografía teórica, México, FCE, 2006.

Schumpeter, Joseph y José Díaz García, Capitalismo, socialismo y democracia, tomo 1, Barcelona, Ediciones Orbis, 1983.

Skinner, Quentin, "The State”, en Terence Ball, James Farr y Russel L. Hanson (eds.), Political Innovation and Conceptual Change, Cambridge, Cambridge University Press, 1989, pp. 90-131.

Summers, Robert, "Los principios del Estado de derecho", en Miguel Carbonell, Wistano Orozco y Rodolfo Vásquez (eds.), Estado de derecho: Concepto, fundamentos y democratización en América Latina, México, Siglo XXI, 2002, pp. 37-59.

Vázquez, Rodolfo, "El Estado de derecho: Una justificación”, en Miguel Carbonell, Wistano Orozco, y Rodolfo Vásquez (eds.), Estado de derecho: Concepto, fundamentos y democratización en América Latina, México, Siglo XXI, 2002, pp. 111-128. 
Documentos legales y resoluciones

Comité de Desc, Observación General No. 3. La índole de las obligaciones de los Estados Parte, 1990.

Corte IDH, Caso González y otras ("Campo Algodonero") Vs. México. Excepción Preliminar, Fondo, Reparaciones y Costas. Sentencia de 16 de noviembre de 2009. Serie C núm. 205, párrafo 306.

Corte IDH, Caso Radilla Pachecoo vs Estados Unidos Mexicanos. Excepciones Preliminares, Fondo, Reparaciones y Costas. Sentencia de 23 de noviembre de 2009. Serie C No. 209, Párrafo 298.

oEA, Convención Americana sobre Derechos Humanos, Organización de Estados Americanos, San José de Costa Rica, noviembre de 1969.

onu, Convención de Viena sobre el Derecho de los Tratados, Organización de las Naciones Unidas, 1969.

\section{Documentos electrónicos}

Human Rights Watch, Neither Rights Nor Security: Killings, Torture and Disappearances in Mexico's "War on Drugs", Reporte de Human Rights Watch, 9 de noviembre de 2011. Disponible en http://www.hrw.org/reports/2011/11/09/neither-rights-nor-security-0 